\title{
Behavior of High Strength Reinforced Concrete Hollow Circular Short Columns under Axial Loads
}

\author{
Ass. Lec. Ghzwan Ghanim Jumah ${ }^{1}$, \\ Building and Construction Engineering Department, University of Technology, Baghdad, Iraq. \\ Corresponding author: email address: ghzwannn@yahoo.com
}

\begin{abstract}
Absrtact
This work deals with investigating the capacity of high strength columns, under axial compression loads. A total of nine circular column with $600 \mathrm{~mm}$ length and $150 \mathrm{~mm}$ outer diameter were tested, three of them were solid as a reference, the remaining six columns were with internal hole of 50 and $75 \mathrm{~mm}$ dimeter. The effect of hole size as well as area of longitudinal steel reinforcement was studied. Area of steel used where 0,301 and $471 \mathrm{~mm}^{2}$ and two hole size were 50 and $75 \mathrm{~mm}$. The results showed that the increasing of longitudinal reinforcement ratio from $0 \%$ (plain) to $2.67 \%$ (steel reinforcement area of $471 \mathrm{~mm}^{2}$ ) for solid column cause an increase in the ultimate strength by $33.6 \%$, while for hollow columns with $75 \mathrm{~mm}$ internal hole the ultimate strength increased up to $33.2 \%$. Increase in hole dimeter from 50 to $75 \mathrm{~mm}$ caused a reduction of columns capacity in all cause, the decrease was up $33 \%$ for columns with 301 $\mathrm{mm}^{2}$ steel area was up to $32 \%$, for columns with $417 \mathrm{~mm}^{2}$.
\end{abstract}

Keywords: Circular column, short column, Ductility, High strength concrete, Hollow column, Steel reinforcement ratio.

Paper History:( Received :31-10-2017; Accepted :13-062018)

\section{Introduction}

Reinforced concrete is the most used material for construction of building. High strength concrete (HSC) is considered as an advantage, the advantage is due to easy to cast in needed shapes. Moreover, the high strength concrete achieves less size and weight of structures members. Using of high strength concrete instead of normal concrete (NC) is demand for high rise building for the purpose of small dimensions members. NC used is incasing the overall weight of the structure and finally needs a huge foundation. In addition, the high strength concrete achieves less deflection and more ductility which give warning before collapse more than the normal concrete. [1]

Adopting hollow columns in structurer will minimize the cost of construction via reducing the size and weight of concrete members. [2]

The use of hollow section columns is often found in tall bridges which is very suitable for the seismic regions like California, New Zealand, Japan and Italy to reduce the weight which contribute the earthquake damage. The high strength concrete hollow columns produce less weight on foundation which leads to minimize the dimensions and cost off foundation. [3]

In this research two types of column were used solid and hollow, with two size of holes and three longitudinal steel area.

\section{Materials and Mix Proportions}

The Materials that used for concrete column manufacturing consist of Ordinary Portland Cement -type I, which confirm to IQS. No.5-1984 [4]. Fine aggregate maximum size $4.75 \mathrm{~mm}$ and coarse aggregate with maximum size of $10 \mathrm{~mm}$, created sand with specific gravity 2.57 and fineness modulus 3.05, confirm to IQS. No.45-1980 [5]. Superplasticizer SP 703 has been used in this work to reduce the water content conforming to (ASTMC494) [6].

Table (1) summarizes the compositions of HSC mix [7]. The compressive strength for concrete of $\left(f_{c}^{-}=52.3 \mathrm{MPa}\right)$ was targeted. Three cylinders with dimension of $100 \times 200 \mathrm{~mm}$ were used to measure the compressive strength of concrete at twenty-eight days according to (ASTMC39). Deformed longitudinal steel bars are being used in this study with nominal diameter of 4, 8 and $10 \mathrm{~mm}$ and conforming to the ASTMA996-M-05. The yield strength $\left(f_{y}\right)$ for $\phi 4 \mathrm{~mm}, \phi$ $8 \mathrm{~mm}$ and $\phi 10 \mathrm{~mm}$ equal to 370,460 and $495 \mathrm{MPa}$, respectively. In this research, the lateral ties were with diameter of $4 \mathrm{~mm}$ at a spacing of $100 \mathrm{~mm}$.

\section{Experimental Program}

This study investigates the effect of using different longitudinal steel reinforcement areas. The axial load capacities of high strength columns are to be determined for different diameters of internal holes. A universal testing machine with 250 Ton maximum capacity was used in the testing of the specified. The tests were carried out in the Structural Engineering Laboratory of the Building \& Constriction Engineering Department at the University of Technology. Details of the columns are given in Table (2). To specify material proportion of concrete three standard control cylinder specimens for each column were casted.

\section{Specimen Geometry and Reinforcement}

The circular column specimens were $600 \mathrm{~mm}$ long and $150 \mathrm{~mm}$ outer diameter with different hole diameters of 0,50 
and $75 \mathrm{~mm}$, as shown in Figure (1) and Figure (2). PVC pipes of 50, 75 and $150 \mathrm{~mm}$ size were used in fabricating mods.

The number of longitudinally reinforced deformed steel was 6 bar with different diameters of 8 and $10 \mathrm{~mm}$. The lateral ties were diameter of $4 \mathrm{~mm}$ bars at spacing of $100 \mathrm{~mm}$ were used. The concrete cover side of $15 \mathrm{~mm}$ was taken in all around columns specimens and $20 \mathrm{~mm}$ cover was provided at the top and bottom face. This cover is provided to prevent direct loading on the bars.

\section{Testing Program}

The tests were conducted under load control test until failure, fixing dial gauges vertically at the ends of columns. The load was increased with increments of $5 \mathrm{kN}$. The crack patterns were observed and the final modes of failure were observed, as shown in Fig. (3). Axial displacements (deformation) and load reading were recorded while testing. All tested specimens were monitored during the test in order to report failure modes.

\section{Results and Discussion}

In this study nine column were tested under axial compression force with variables listed in Table (2).

\section{a. Effect of hole size}

Three columns without steel reinforcement (Plain) (S-00-00, $\mathrm{H}-00-50$ and $\mathrm{H}-00-75)$ have been tested under axial compression load, and results were listed in Table (3).The axial load capacity decreased, when the size of hole increase from 0 to $75 \mathrm{~mm}$, the decreased percentage was 26.8 and 33.2 $\%$ for size of holes 50 and $75 \mathrm{~mm}$ respectively, as compared with the reference $\mathrm{S}-00-00$. The presence of a hole cause a reduction in column concrete area, which cause reduction in column capacity [8].Fig. (4), shows load-deflections relation of columns without steel reinforcement, in which the brittle behavior was noticed and less deflection for all.

\section{b. Effect of the longitudinal steel reinforcement area}

Table (4), indicates that increasing the steel reinforcement area cause an enhancement in column capacity for all specimens, for solid column the increase in steel reinforcement area from 0 to $301 \mathrm{~mm}^{2}$ the axial load capacity increased by $10.1 \%$, and from 0 to $471 \mathrm{~mm}^{2}$ the increase was $33.6 \%$.

While for column with $50 \mathrm{~mm}$ hole the increase was 14.8 and $25.6 \%$ for steel reinforcement area 301 and $471 \mathrm{~mm}^{2}$, respectively.

Column with $75 \mathrm{~mm}$ hole the increased percent of column capacity was 12.2 and $23.0 \%$ for steel reinforcement area 301 and $471 \mathrm{~mm}^{2}$, respectively. As shown in Fig. (5).

Through the Table (5), it could be seen that using the 301 $\mathrm{mm}^{2}$ area of steel reinforcement and changing of hole diameter from 0 to 50 and $75 \mathrm{~mm}$ cause a reduction in capacity 23.8 and $32.0 \%$, respectively.

While when using $\left(471 \mathrm{~mm}^{2}\right.$ of longitudinal steel reinforcement) the decreased percentage was 31.3 and 38.5, respectively.

\section{c. Axial deformation}

The axial deformation at the ends of the column were measured using dial gages with accuracy of $0.01 \mathrm{~mm}$. The results were listed in Table (6). It was observed that the increased in size of holes 0 to 50 and $75 \mathrm{~mm}$, cause increase in axial deformation 55.5 and $100.1 \%$. Moreover, column $\mathrm{H}-$ 00-75 shows higher axial displacement than column $\mathrm{H}-00-50$ and S-00-00.

From Table (7), it was indicated that increasing the steel reinforcement area will cause an increase in the capacity of column. For solid column increasing the steel reinforcement area from 0 to $301 \mathrm{~mm}^{2}$ cause an increase by $11.3 \%$ in axial deformation and when the steel reinforcement area $471 \mathrm{~mm}^{2}$ the increase reach to $33.3 \%$. While for hollow column with $50 \mathrm{~mm}$ size of hole the increase in axial deformation was 28.6 and $35.7 \%$ for steel reinforcement area $301 \mathrm{~mm}^{2}$ and 471 $\mathrm{mm}^{2}$, respectively.

Column with $75 \mathrm{~mm}$ size of hole the increase in axial deformation reached 35.3 and $41.2 \%$ for columns with steel reinforcement area $301 \mathrm{~mm}^{2}$ and $471 \mathrm{~mm}^{2}$, respectively. It was noted that increased in steel area change the mode of failure from brittle to ductile and more deformation was recorded.

\section{d. Axial load capacity -axial deformation}

Figs. (4, 6 and 7), show the axial load-deformation relationships of concentrically loaded circular columns measured during the test.

The hollow column H-10-75 with $471 \mathrm{~mm}^{2}$ longitudinal steel reinforcement area shows the highest axial deformation and the less axial load capacity. This reduction in capacity was because of presence hollow column that cause to reduction of concrete area.

The axial load capacity with column axial deformation curve consists of one main ascending part. The initial stage of loading before reaching the ultimate load, this part was divided into two distinct stages of behavior. The first can be described by an approximately linear constitutive relationship load and deformation. The second starts when the concrete tends to crack. At this stage the stiffness of the column decreased as indicated by the reduction in slope of the axial load-deformation curves. The final stage takes place when the longitudinal reinforcement begins to bend and the applied load is mostly carried by the core of concrete while the crack width in concrete increased and failure become clear. 


\section{e. Column Ductility}

The ability of columns to deform without important losses of strength is Ductility and it was calculated due as in equation (1), since, the control loading procedures of testing columns were executed, but the reaction of hollow columns was not possible to trace even after the peak load.

$$
\text { Ductility }=\frac{\Delta u}{\Delta y}
$$

Where:

$\Delta \mathrm{u}:$ Ultimate axial deflection

$\Delta \mathrm{y}:$ Yield axial deflection

From Table (7), as expected, the increase of the hollow size would increase the ductility. Also, increasing the reinforcement ratio leads to increase in the ductility for hollow and solid columns.

\section{Failure Modes}

In all tested specimens, the failure starts as cracks that occur approach the ends causing crashing of concrete, the columns and with the load increase the mid span of column will start to pull out side and split the concrete that make in tension, so that these cracks will move upward towards the mid-height of the column. The width of the cracks increased with load increase till the splitting of the concrete occurs, as indicated in Fig. (8).

The main observation in the tests which may have to be mentioned here is the sudden explosive of failing for columns without reinforcement. As well as to complete crashing of solid column, it is evidently observed that the increase of the area of reinforcement steel significantly enhances the ductility and stiffness the tested columns opposed to the case of columns without steel reinforcement content. In addition, increasing the size of holes leads to improvement in the ductility of hollow column as indicated. Figs. (4, 6 and 7).
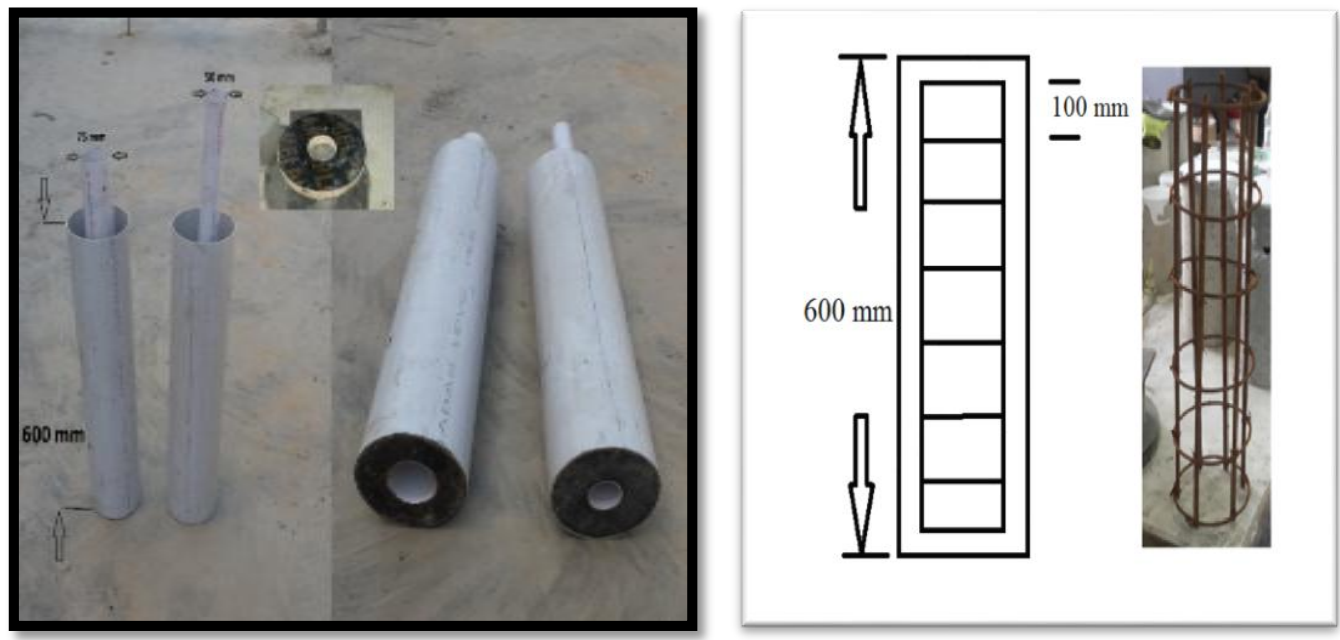

Figure 1 Set-up and configuration of tested columns 


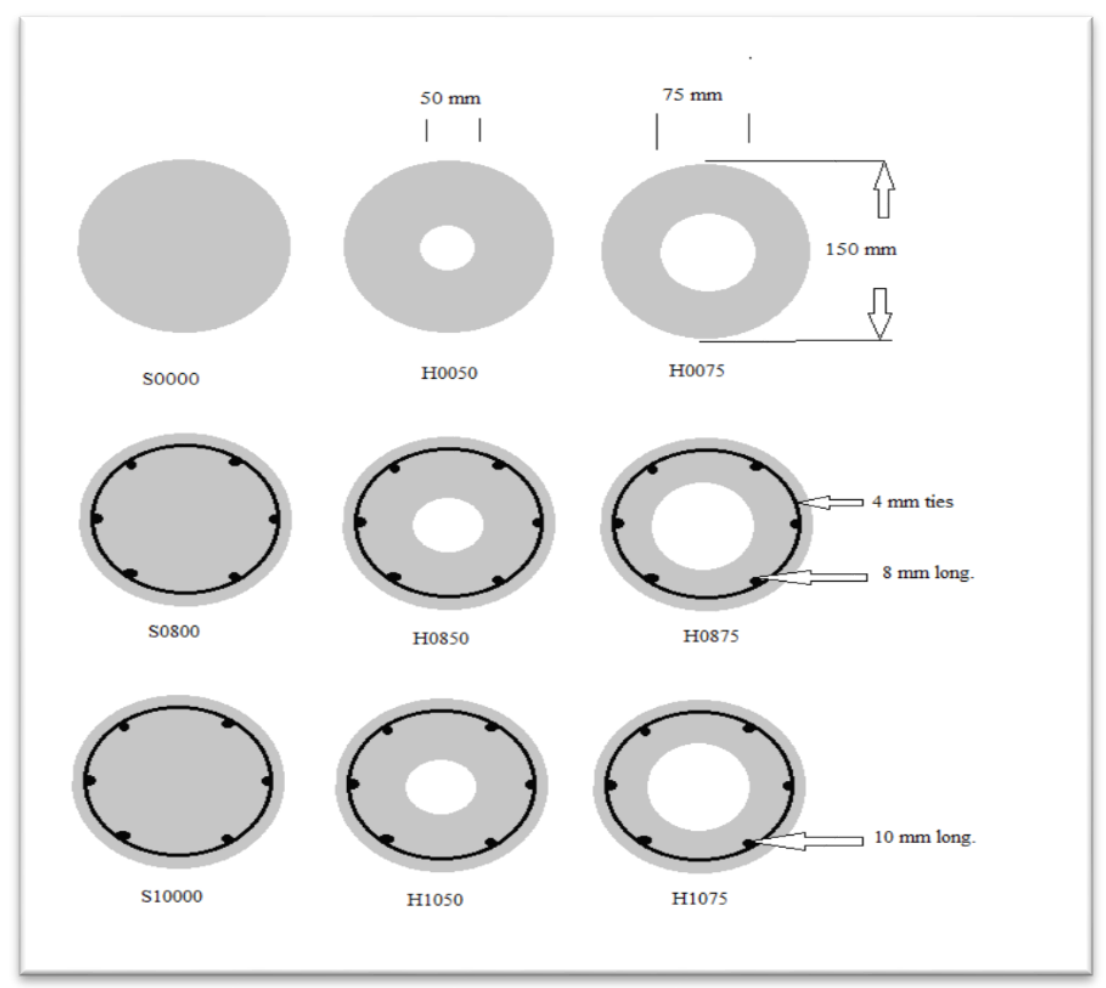

Figure 2 Details of solid and hollow columns reinforced

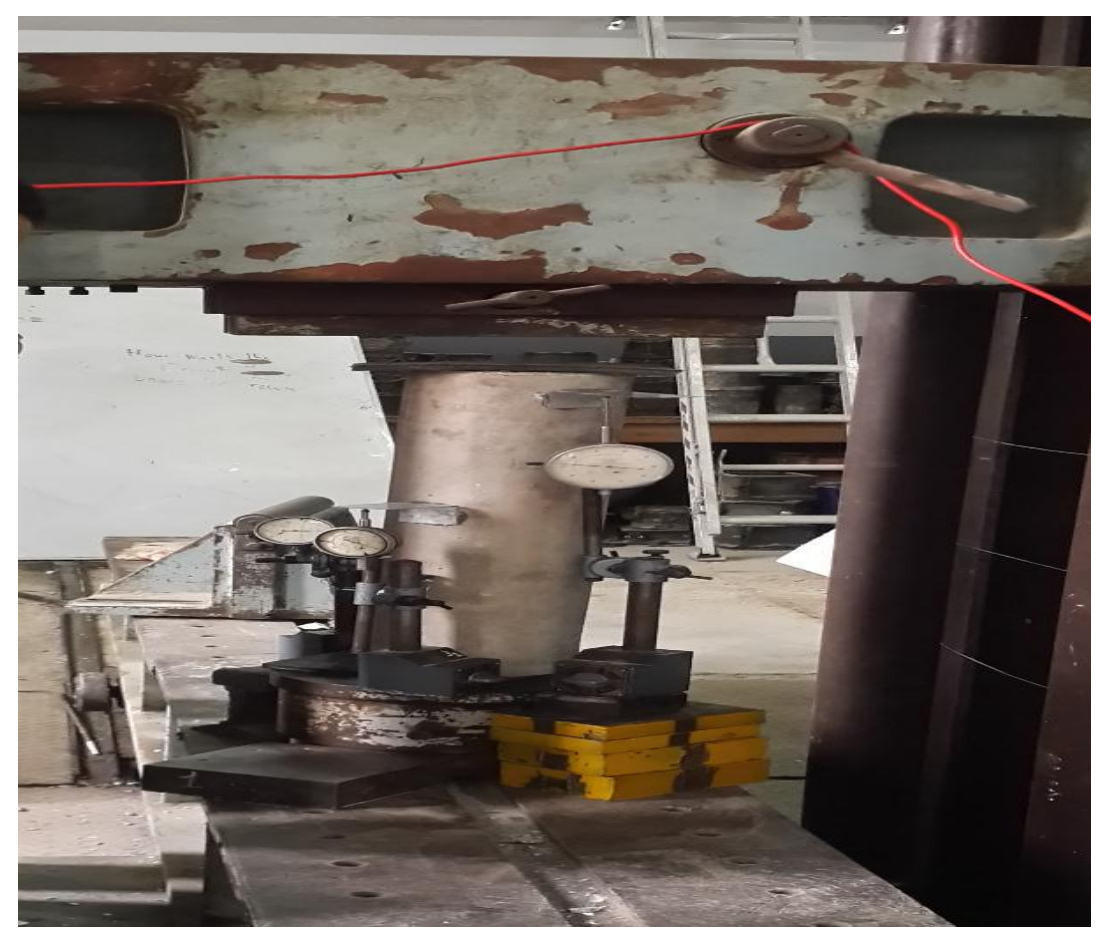

Figure 3 Test set-up 


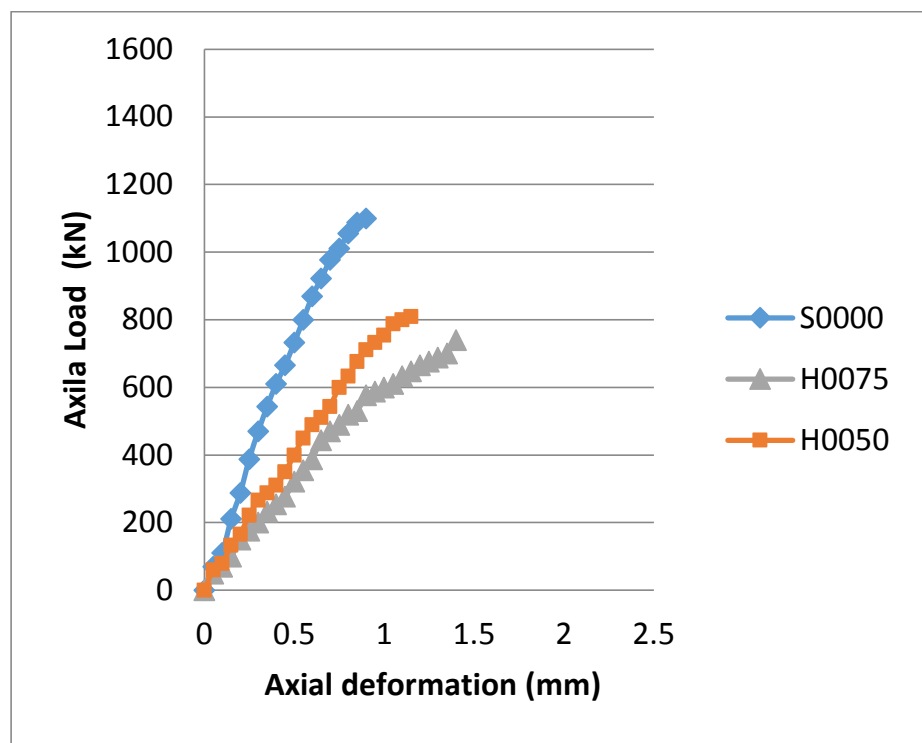

Figure 4 Load-deformation relation without reinforcement

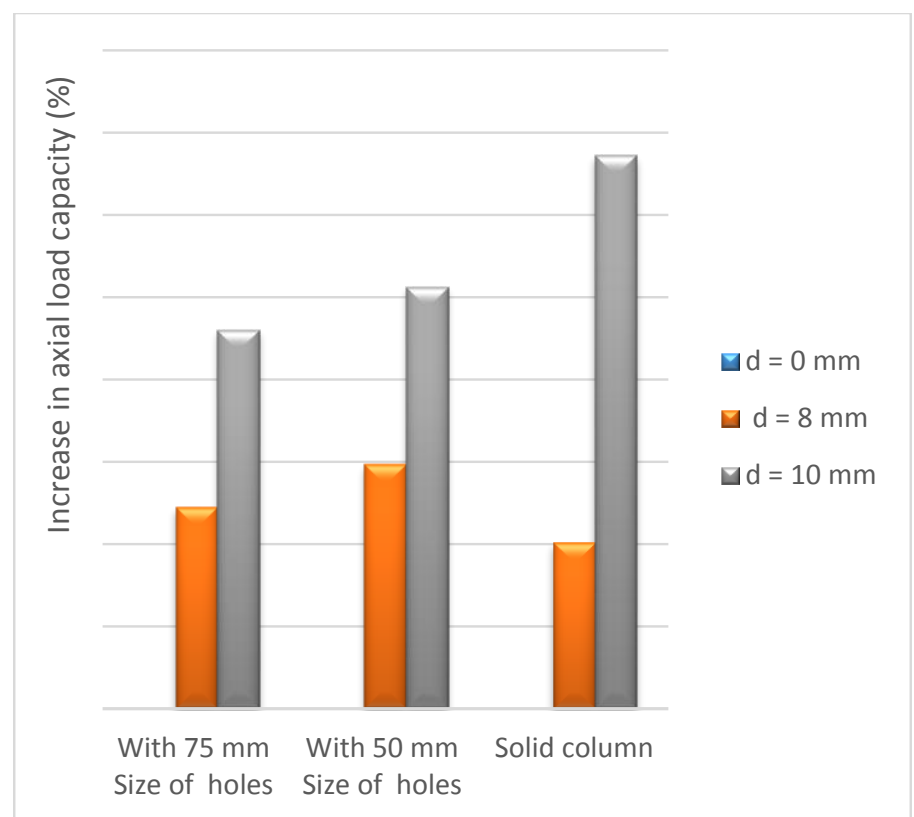

Figure 5 Increase in axial load capacity. 


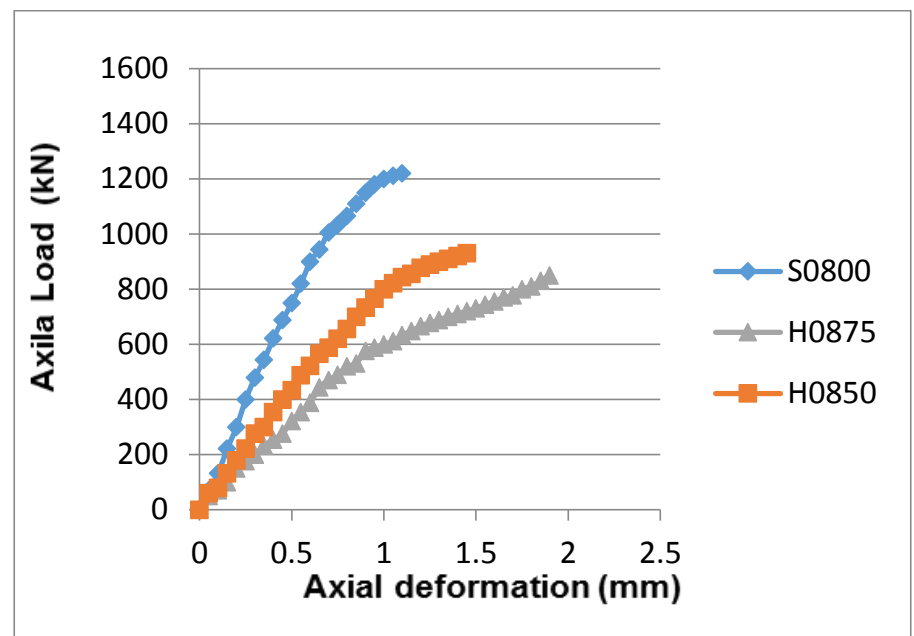

Figure 6 Load-deformation relation with $301 \mathrm{~mm}^{2}$ reinforcement area

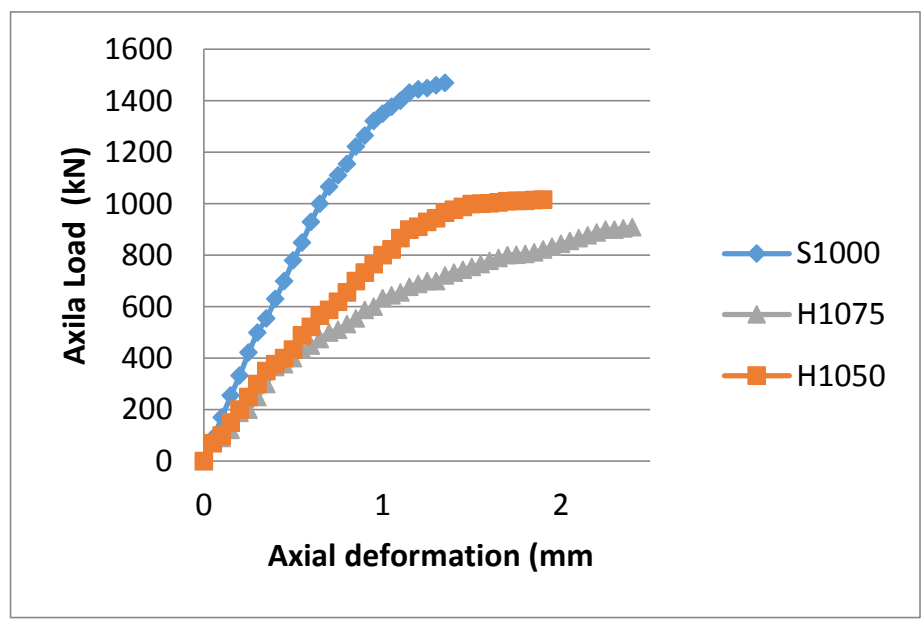

Figure 7 Load-deformation relation with $471 \mathrm{~mm}^{2}$ reinforcement area
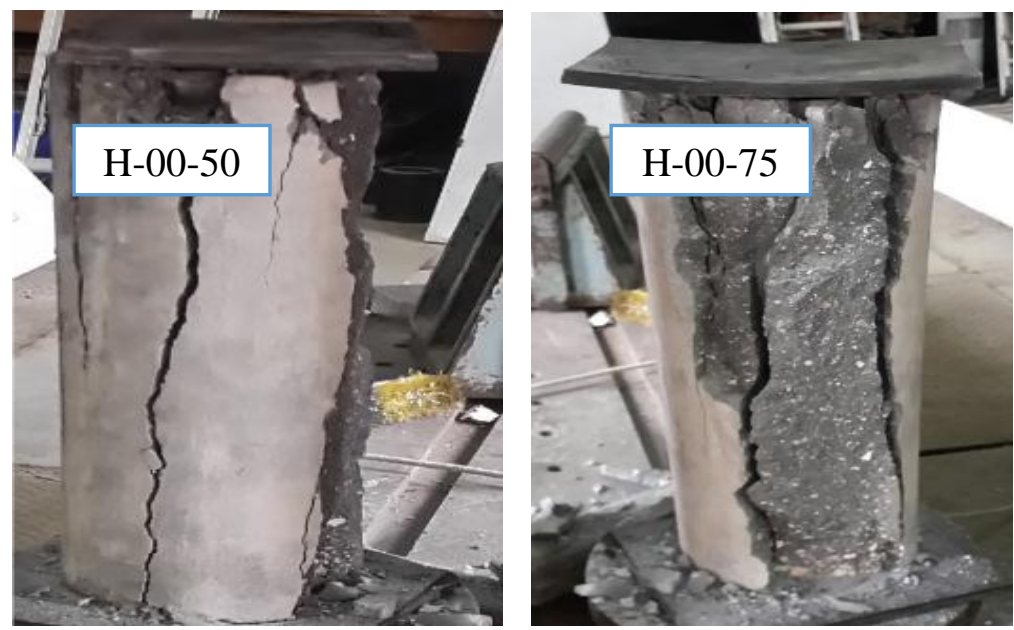

a- Column without steel reinforcement area for hollow column 

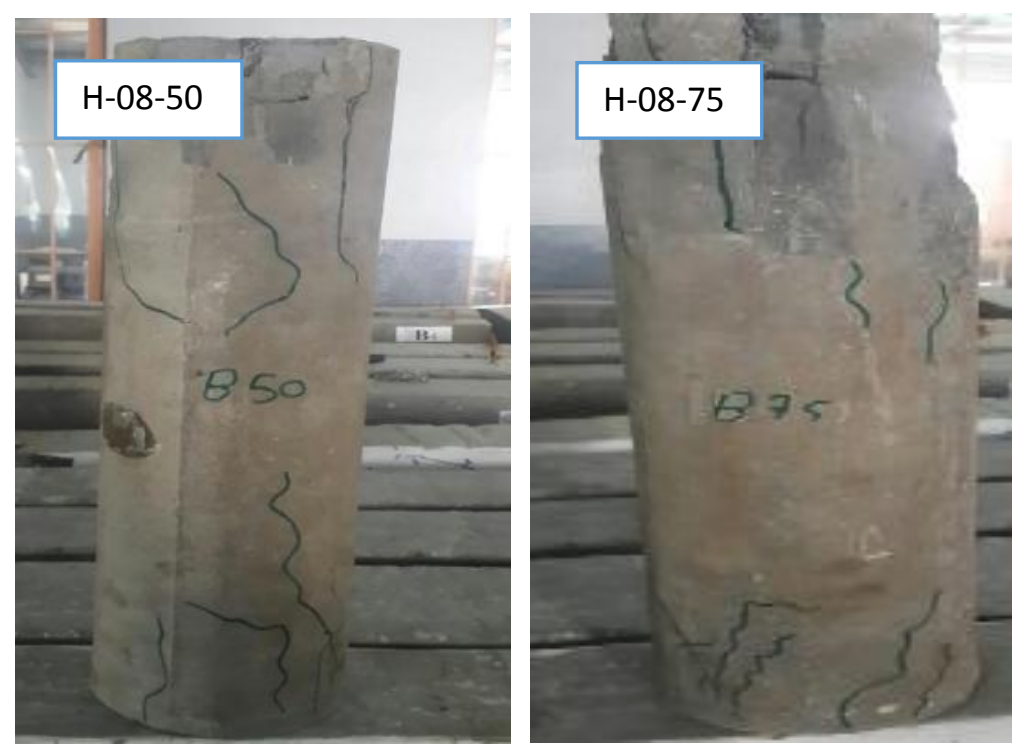

b- Column with steel reinforcement area $301 \mathrm{~mm}^{2}$ for hollow column
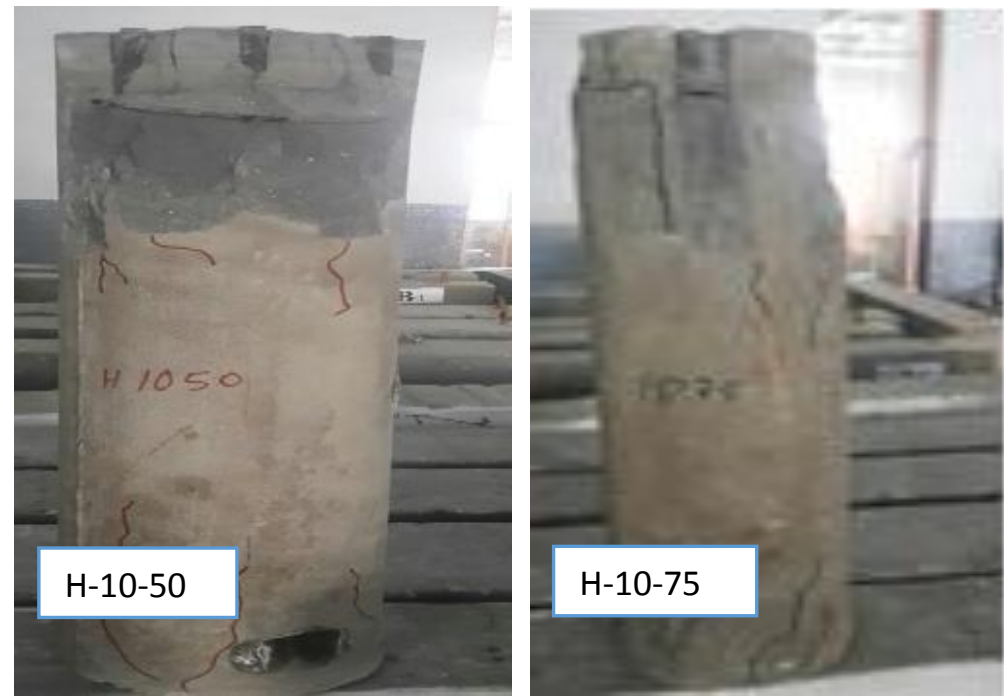

c- steel reinforcement area $471 \mathrm{~mm}^{2}$ for hollow column
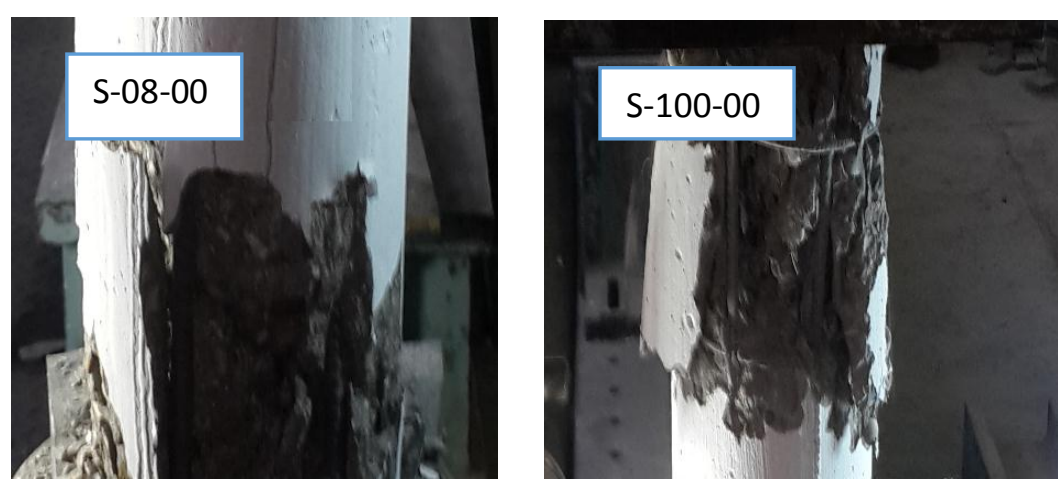

d- Solid columns with different steel reinforcement area Figure 8 Modes of failure for tested hollow columns 


\section{Conclusions}

From previous results the following conclusions may be drawn:

1. Hollow columns with different size of holes for each reinforcement area showed similar behavior, in spite of that columns of $50 \mathrm{~mm}$ size of holes diameter were of higher capacity than that of $75 \mathrm{~mm}$ size of holes.

2. Hollow column without reinforcement were of sudden longitudinal splitting failure. Solid plain column was of $27 \%$ and $32 \%$ higher capacity than that of hollow column of $50 \mathrm{~mm}$ and $75 \mathrm{~mm}$ size of holes, respectively.

3. Using higher reinforcement area increase both capacity and ductility for the studies columns. Both the longitudinal and lateral reinforcement were preventing sudden brittle failure.

4. Solid columns with reinforcement area $471 \mathrm{~mm}^{2}$ (six 10 mm bars) show higher ductility and was of less cracks than that of solid column with $301 \mathrm{~mm}^{2}$ (six $8 \mathrm{~mm}$ bars). The appearance of cracks was delayed for higher reinforced solid columns.

5. The gain in strength of solid columns with reinforcement area $471 \mathrm{~mm}^{2}$ (six $10 \mathrm{~mm}$ bars) was $17 \%$ higher than that of $301 \mathrm{~mm}^{2}$ (six $8 \mathrm{~mm}$ bars).

6. Increasing reinforcement areas were of lower effect on hollow columns than that on solid columns. The increase in reinforcement area from 301 to $471 \mathrm{~mm}^{2}$ was $10 \%$ increase in strength for hollow columns with $50 \mathrm{~mm}$ size of holes.

\section{Reference}

[1] Kusumawardaningsih, Y and Hadi, MNS (2010). Comparative "Behavior of Hollow Columns Confined with FRP Composites." Journal of Composite Structures. Volume 93, Issue 1, Dec, pp. 198-205.

[2] V. Yazici, "Strengthening Hollow Reinforced Concrete Columns with Fiber Reinforced Polymers," University of Wollongong, p. 153, 2010.

[3] M. J. N. Priestley and J. I. Hoshikuma, "Flexural Behavior of Circular Hollow Columns with A Single Layer of Reinforcement under Seismic Loading," Final Research Report for Caltrans under Contract No. 59A0051. University of California no. 59, pp. iii-79, 2000.

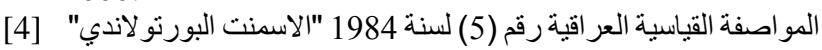
، الجهاز المركزي للتقييس و السيطرة النوعية.

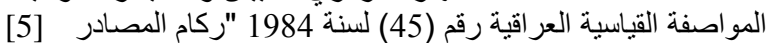

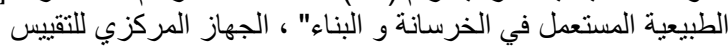

16] ASTM C494, "Standard Specification السيطرة النوعية. Admixtures for Concrete," Am. Soc. Test. Mater., no. February, pp. 1-9, 2015.

[7] W. I. Khalil, I. N. Gorgis, and Z. R. Mahdi, "Behavior of High Performance Fiber Reinforced Concrete Columns," ARPN Journal of Engineering and Applied Sciences vol. 7, no. 11, pp. 1455-1467, 2012.
[8] F. Khairallah, "Mechanical behavior of confined selfcompacting reinforced concrete circular columns under concentric axial load capacitying," Ain Shams Eng. J., vol. 4, no. 4, pp. 641-649, 2013. 